This item was submitted to Loughborough's Research Repository by the author.

Items in Figshare are protected by copyright, with all rights reserved, unless otherwise indicated.

\title{
Effect of various efficient vulcanization cure systems on the compression set of a nitrile rubber filled with different fillers
}

PLEASE CITE THE PUBLISHED VERSION

https://doi.org/10.1002/app.41512

\section{PUBLISHER}

(C) John Wiley \& Sons

\section{VERSION}

AM (Accepted Manuscript)

\section{PUBLISHER STATEMENT}

This work is made available according to the conditions of the Creative Commons Attribution-NonCommercialNoDerivatives 4.0 International (CC BY-NC-ND 4.0) licence. Full details of this licence are available at: https://creativecommons.org/licenses/by-nc-nd/4.0/

\section{LICENCE}

CC BY-NC-ND 4.0

\section{REPOSITORY RECORD}

Movahed, Saeed Ostad, Ali Ansarifar, and Farnaz Mirzaie. 2017. "Effect of Various Efficient Vulcanization Cure Systems on the Compression Set of a Nitrile Rubber Filled with Different Fillers". figshare. https://hdl.handle.net/2134/26466. 


\title{
Effect of various efficient vulcanization (EV) cure systems on the compression set of a nitrile rubber filled with different fillers
}

\author{
Saeed Ostad Movahed ${ }^{1^{*}}$, Ali Ansarifar ${ }^{2}$, Farnaz Mirzaie ${ }^{1}$ \\ ${ }^{1}$ Polymer group, Faculty of Sciences, Ferdowsi University of Mashhad, Mashhad, Iran \\ ${ }^{2}$ Department of Materials, Loughborough University, Leicestershire LE11 3TU UK
}

\begin{abstract}
Effect of various efficient vulcanization sulfur cure systems (EV) on the compression set of a nitrile rubber filled with carbon black and silica/silane fillers was examined. The cure systems had different amounts of thiuram and sulfenamide accelerators and elemental sulfur, whilst the loading of zinc oxide and stearic acid activators was kept constant. The fillers had surface areas from 35 to $175 \mathrm{~m}^{2} / \mathrm{g}$. In this study, the lowest compression set was measured for the rubber filled with carbon black with $78 \mathrm{~m}^{2} / \mathrm{g}$ surface area, which was cured with an EV cure system made of a small amount of elemental sulfur and large amounts of the two accelerators. Interestingly, a small change in the amount of elemental sulfur had a bigger effect on the compression set than did large changes in the loading of the accelerators in the cure system. Among the fillers, carbon black caused less compression set of the rubber vulcanizate than the silica/silane system did.
\end{abstract}

*Correspondence to: S.Ostad Movahed (s-ostad@um.ac.ir) 


\section{INTRODUCTION}

Compression set measures the ability of cured rubber to recover its original shape after the deforming force is removed, and is the ratio of elastic to viscous components of a rubber response to a given deformation. ${ }^{1} \mathrm{~A}$ compound with the least compression set has the highest level of elasticity and consequently, it has the least viscous property. This is usually expressed as the percentage of the compression which is not recovered within a short time after release. Generally, the lower the compression set percentage the better. Compression set is an important property of industrial rubber articles such as sealants. Seals for automotive body applications for example windows, hoods, trunks and doors, and building applications such as windows glazing, gaskets and weather strips, should have dimensional stability to provide low compression set, and offer outstanding sealing characteristics over a broad range of temperature. Such seals must be capable of sealing out noise, wind and water, while providing long-term ultraviolet light resistance. At the same time, the material used in making seals must offer the degree of flexibility required for a particular application. ${ }^{2}$

Several papers have reported factors affecting mechanical properties including compression set of rubber vulcanizates. ${ }^{3-7}$ For example, Morrell and co-workers ${ }^{6}$ investigated accelerated thermal ageing of NBR rubber O-rings in air whilst under $12.5 \%$ compression at temperatures up to $110^{\circ} \mathrm{C}$. Their results indicated that the predominant reaction contributing to compression set was oxidative degradation of the rubber. The degradation process leading to the compression set was oxidative crosslinking in nature. Additionally, the solvent swell tests showed a correlation between the compression set and crosslink density. Chang $^{7}$ investigated effect of changing 
Mooney viscosity on the hardness, elongation at break and compression set of a sulfurcured NBR rubber and reported reduction in the compression set as the Mooney viscosity was increased. Evidently, the compression set of NBR was influenced by many factors.

Sulfur vulcanization uses accelerator to open elemental sulfur ring to form crosslinks with the rubber chains. Accelerators, in simplest terms, hasten the cleavage of the sulfur ring and formation of thiyl and polysulfenyl radicals. ${ }^{8}$ Sulfenamide accelerators such as N-cyclohexyl-2-benzothiazole sulfenamide (CBS) are safeprocessing, delayed action accelerators and are most widely used as primary accelerators due to their superior scorch safety. CBS is rarely used in sulfur cure systems without a secondary accelerator. The most widely used secondary accelerators with CBS are from the thiurams group. The thiuram accelerators for instance tetramethylthiuram disulfide (TMTD), are fast curing, sulfur-bearing accelerators and possess short scorch safety when used as a primary accelerator. ${ }^{9}$ In efficient cure systems (EV), there is low level of elemental sulfur, i.e. $0.5 \mathrm{phr}$, with high accelerator content (5-6 phr). EV cure systems have predominantly high mono-sulfidic and little or no polysulfidic crosslink content. ${ }^{10,11}$

Mechanical properties of sulfur-cured rubber vulcanizates are affected by crosslink density changes. For natural rubber (NR), styrene-butadiene rubber (SBR), and ethylene-propylene diene rubber (EPDM), tensile strength and tear strength improved as a function of crosslink density, reaching some optimum values and then decreased as the crosslink density was raised further. ${ }^{12}$ Another study ${ }^{10}$ investigated effect of various types of sulfur-cure systems on the mechanical properties of NR and reported 
similar findings. But, there has been relatively limited data available on the effect of different EV sulfur cure systems on the compression set of NBR. Of particular interest was to determine how changes in the loading of CBS and TMTD accelerators and elemental sulfur at a fixed loading of activators in EV sulfur cure system affected the compression set of NBR filled with carbon black and silica solid fillers. This was important because NBR is used extensively to manufacture O-rings and industrial gaskets for high temperature and corrosive environments. ${ }^{13}$ NBR is a non-crystallizing rubber unlike NR and must be reinforced with solid fillers such as carbon black and silica to improve its mechanical properties.

Carbon blacks, synthetic silicas, quartz, and metal oxides which have large surface areas ranging from 30 to $400 \mathrm{~m}^{2} / \mathrm{g}$ are very effective in improving mechanical properties of rubber ${ }^{14}$ Carbon blacks and silicas are the most widely used fillers in rubber reinforcement and in recent years silicas have been replacing carbon blacks in many industrial rubber compounds. However, silicas are acidic ${ }^{15}$ and polar ${ }^{16}$ because of the presence of silanol or hydroxyl groups on their surfaces. This causes unacceptably long cure times and slow cure rates, ${ }^{17}$ and also loss of crosslink density in sulfur-cured rubbers. ${ }^{18}$ To remedy the problems aforementioned, bifunctional organosilanes also known as coupling agents, for example bis(3-triethoxy silylpropyl)-tetrasufide (TESPT), are added to modify silica. The addition of an increasing loading of TESPT improved dispersion of silica particles in rubber. ${ }^{19}$ Silica and TESPT interact in two ways. Firstly, silica and TESPT are mixed together in the required ratio and homogenized in an additional preliminary mixing stage. ${ }^{20}$ Alternatively, silanization is carried out in situ. This 
is usually done in an internal mixer at the first stage of mixing, where TESPT is added together with or after the addition and dispersion of the silica. ${ }^{21}$

Effect of an increasing loading of TESPT on the mechanical properties of natural rubber (NR) filled with a high loading of precipitated amorphous white silica was investigated. The silanization was performed in situ. There was evidence that the silica was poorly dispersed in the rubber and probably had not been properly silanized before addition to the raw rubber. ${ }^{22}$ In later work, large amount of TESPT pre-treated precipitated silica was mixed with NR and the filler dispersion was investigated by scanning electron microscopy (SEM). The silica particles dispersed well in the rubber matrix and the mechanical properties were significantly better than those measured previously for NR containing an equivalent amount of silica and TESPT which was prepared in situ. ${ }^{23} \mathrm{~A}$ similar behavior was also observed when a high level of TESPT pre-treated precipitated silica was used in $\mathrm{NBR}^{24}$ In addition, the rubber reactive tetrasulfane groups of TESPT reacted with the rubber chains in the presence of accelerator to form stable covalent crosslinks or chemical bonds which increased the rubber-filler interaction. This was beneficial to the reinforcement of the rubber properties. $^{23,24}$

In this study, effect of different EV sulfur cure systems on the compression set of an NBR rubber filled with carbon black and silica/TESPT fillers of different surface areas was investigated. The loading of zinc oxide and stearic acid activators in the cure system and carbon black and silica fillers in the rubber were kept constant, though the amount of elemental sulfur was changed. In addition to the compression set, the scorch 
and optimum cure times, cure rate index, crosslink density, tensile strength, elongation at break, and hardness of the rubber vulcanizates were also measured.

\section{EXPERIMENTAL}

\section{Materials - Rubber, filler and rubber chemicals}

The raw rubber used was acrylonitrile-butadiene rubber (NBR, 34\% Acrylonitrile, LG 6240, LG Chem, Korea). The reinforcing fillers were untreated precipitated amorphous white silica-type Ultrasil VN3, Coupsil 8113 (Evonik Industries AG, Germany), high abrasion furnace (N330), fast extruding furnace (N550), and general purpose furnace (N660) carbon blacks (Pars Carbon Ltd., Saveh, Iran). Coupsil 8113 is precipitated silica-type Ultrasil VN3, the surface of which was pre-treated with TESPT before use in the rubber. It has $11.3 \%$ by weight TESPT, $2.5 \%$ by weight sulfur (included in TESPT), $175 \mathrm{~m}^{2} / \mathrm{g}$ surface area (measured by $\mathrm{N}_{2}$ adsorption) and an average particle size of 20$54 \mathrm{~nm}$. The carbon blacks N330, N550 and N660 have 78, 40, and $35 \mathrm{~m}^{2} / \mathrm{g}$ surface areas (measured by $\mathrm{N}_{2}$ adsorption), and average particle sizes of 31,53, and $63 \mathrm{~nm}$, respectively. ${ }^{25-26}$

In addition to the raw rubber and reinforcing fillers, the other ingredients were tetramethylthiuram disulfide (Perkacit TMTD, accelerator, Scheme 1, Flexsys), Ncyclohexyl-2-benzothiazole sulfenamide (Santocure CBS, accelerator, Scheme 2, Flexsys), zinc oxide (activator, Harcros Durham Chemicals, UK), stearic acid (activator, Anchor Chemical Itd, UK), elemental sulfur (curing chemical, Solvay Barium Strontium, Hannover, Germany), and processing oil. The processing oil was a synergistic blend of 
fatty acid derivatives with selected polarities (Struktol WB 42; Struktol Company of America). It was claimed that the oil improved filler dispersion in the rubber.

\section{Mixing}

The raw rubber was mixed with the reinforcing fillers for 6 min in a semi industrial Banbury mixer (Misagh Afzar co., Iran) with counter rotating tangential rotors. The rotor speed was set at $62 \mathrm{rpm}$. The volume of the mixing chamber was 12 liter, and it was $80 \%$ full. In the case of the untreated silica, liquid TESPT equivalent to the amount present in Coupsil 8113 was added to the rubber in the Banbury mixer. After mixing ended, the chemical curatives and processing oil were added to the rubber compounds on a two roll mills and mixed for another $10 \mathrm{~min}$ at ambient temperature. The two roll mills had the following dimensions: diameter $25 \mathrm{~cm}$ and length $75 \mathrm{~cm}$. Computer software was used for controlling the mixing conditions and storing data. The Banbury mixer and two roll mills were equipped with cooling system. The compounds formulations were summarized in Table 1. The temperature variations of some carbon black- and silica-filled rubber compounds with CBS or TMTD as a function of mixing time were shown in Figure 1. The lowest and highest temperatures during mixing were $50-96^{\circ} \mathrm{C}$, respectively.

\section{Cure properties of the rubber compounds}

The scorch time $\left(t_{s 1}\right)$, which is the time for the onset of cure, and the optimum cure time $\left(t_{90}\right)$, which is the time for the completion of cure, were determined from the cure traces generated at $160 \pm 2^{\circ} \mathrm{C}$, using an oscillating disc rheometer curemeter (ODR, SANTAM SRT-200B, Santam Company) at an angular displacement of $\pm 3^{\circ}$ and a test frequency 
of $1.7 \mathrm{~Hz}$. These tests ran for up to $18 \mathrm{~min}$. $\Delta$ torque, which is the difference between the maximum and minimum torque values on the cure trace of the rubber and is an indication of crosslink density changes in the rubber, was also determined from the cure traces. Figure 2 shows typical cure traces produced in the ODR. The cure rate index $(\mathrm{CRI})$, which is a measure of the rate of curing in the rubber, was calculated using ${ }^{27}$

$$
\mathrm{CRI}=100 /\left(t_{90}-t_{s 1}\right)
$$

All the test results were summarized in Table 2.

\section{Curing of the rubber compounds, test pieces, and test procedure}

After the cure properties were measured (Table 2), the rubber compounds were cured in a compression mold at $160^{\circ} \mathrm{C}$ and a pressure of 160 atm. Pieces of rubber, each approximately $57 \mathrm{~g}$ in weight, were cut from the milled sheet. Each piece was placed in the center of the mold to enable it to flow in all directions when pressure was applied to prevent anisotropy from forming in the cured rubber. For determining the mechanical properties of the rubber vulcanizates, sheets $15 \mathrm{~cm}$ by $15 \mathrm{~cm}$ in dimensions and approximately $2.3 \mathrm{~mm}$ thick, were cured from which various samples for further tests were cut.

\section{Measurement of the crosslink density and sol content of the rubber compounds}

The solvent used for the sol content and crosslink density (CLD) determinations was toluene. For the determination, $5 \mathrm{~g}$ of the rubber was placed in $300 \mathrm{ml}$ of the solvent in labeled bottles, and allowed to swell for 16 days at $21^{\circ} \mathrm{C}$. The sample weight was measured every day until it reached equilibrium. The solvent was then removed. The samples were dried in air for $9 \mathrm{~h}$ and then in an oven at $85^{\circ} \mathrm{C}$ for $24 \mathrm{~h}$, and allowed to 
stand for an extra $24 \mathrm{~h}$ at $23^{\circ} \mathrm{C}$ before reweighing. The CLD was calculated using the Flory-Rehner equation ${ }^{28}$ :

$$
\rho_{c}=-\frac{1}{2 V_{s}} \frac{\ln \left(1-v_{r}^{0}\right)+v_{r}^{0}+x\left(v_{r}^{0}\right)^{2}}{\left(v_{r}^{0}\right)^{1 / 3}-v_{r}^{0} / 2}
$$

where $\rho_{c}$ is the $\operatorname{CLD}\left(\mathrm{mol} / \mathrm{m}^{3}\right), V_{s}$ is the molar volume of toluene $\left(1.069 \times 10^{-4} \mathrm{~m}^{3} / \mathrm{mol}\right.$ at $\left.25^{\circ} \mathrm{C}\right), v_{r}^{0}$ is the volume fraction of rubber (polymer) in the swollen gel, and $\chi$ is the interaction parameter, which was calculated using the following equations: ${ }^{29,30}$

$$
\begin{array}{r}
\chi=0.429+0.218 v_{r}^{o} \\
v_{r}^{o}=\frac{1}{1+\frac{d_{r}}{d_{s}}\left(\frac{1-f_{\text {sol }}}{1-f_{\text {sol }}-f_{f i l}}\right)\left(\frac{w_{S}}{w_{0}}-1\right)}
\end{array}
$$

where $d_{r}$ and $d_{s}$ are the densities of the rubber and solvent, respectively; $f_{s o l}$ is the weight fraction of soluble material in the initial sample (sol fraction); $f_{f i l}$ is the initial weight fraction of filler in the sample; $w_{s}$ is the weight of the swollen gel; and $w_{0}$ is the weight of the dried sample.

Note that the Krause correction was not made because the results were used primarily to compare the CLD of the compounds tested. The sol content was calculated as a percentage, using the following equation:

$$
\text { Sol } \%=f_{\text {sol }} X 100=\frac{w_{i}-w_{0}}{w_{i}} \times 100
$$


where $w_{i}$ is the initial weight of the sample. Results from these experiments were summarized in Table 3.

\section{Measurement of the compression set of the rubber vulcanizates}

The compression set of the rubber vulcanizates was measured at $25 \%$ compression at $100{ }^{\circ} \mathrm{C}$ for $24 \mathrm{~h}$, using cylindrical samples, $13.1 \mathrm{~mm}$ thick and $28.9 \mathrm{~mm}$ in diameter, according to the procedure described in ASTM D395-03. The samples were placed in a compression set testing apparatus (Taha Ghaleb Toos Co. Iran) and at the end of the test, the samples were removed and allowed to cool at room temperature for $30 \mathrm{~min}$ and then the set was calculated using the following expression:

$$
\text { Compression set }=\frac{\text { Initial thickness }- \text { Final thickness }}{\text { Initial thickness } \times 25 \%} X 100
$$

This was repeated on three different samples, and the median of the three readings was reported. The results were summarized in Table 4.

\section{Determination of the tensile properties and hardness of the rubber vulcanizates}

The tensile strength and elongation at break of the rubber vulcanizates were determined in uniaxial tension in a SANTAM STM-20 mechanical testing machine, using standard dumbbell test pieces (95 mm long with a central neck $26 \mathrm{~mm}$ long and $2.3 \mathrm{~mm}$ wide). The test pieces were die-stamped from the sheets of cured rubber. The tests were performed at $21{ }^{\circ} \mathrm{C}$ and a cross-head speed of $500 \mathrm{~mm} / \mathrm{min} .{ }^{31}$ SANTAM computer software was used for storing and processing the data. The hardness was measured using cylindrical samples, $12.5 \mathrm{~mm}$ thick and $29.0 \mathrm{~mm}$ in diameter. The samples were placed in a Shore A durometer hardness tester (Shore Instrument \& Mfg., Co., New 
York) and the hardness was measured at $23.5^{\circ} \mathrm{C}$ and a reading was taken after $15 \mathrm{~s}$. This was repeated at three different positions on each sample, and the median of the three readings was reported. ${ }^{32}$ The results were reported in Table 4.

\section{RESULTS AND DISCUSSION}

\section{Effect of various EV cure systems on the compression set of the rubber vulcanizate}

To study effects of various EV sulfur cure systems on the compression set of the rubber vulcanizate filled with carbon black and silica fillers, compounds with various CBS (primary accelerator) to TMTD (secondary accelerator) weight ratios were prepared (compounds 1-40, Table 1). The CBS/TMTD weight ratios were $0.33,1$ and 3 for all the compounds tested. However, the amount of each accelerator varied from one compound to another. For example, in compounds 2-4, the loading of CBS was increased from 0.4 to $1.2 \mathrm{phr}$ and that of TMTD decreased from 1.2 to $0.4 \mathrm{phr}$, and in compounds 7-9, the amount of CBS was raised from 1.25 to $3.75 \mathrm{phr}$ and that of TMTD decreased from 3.75 to $1.25 \mathrm{phr}$ to produce the weight ratios mentioned above. Similarly, for compounds 12-39, the loading of CBS was raised from 2 to $6 \mathrm{phr}$ and that of TMTD decreased from 6 to $2 \mathrm{phr}$ to produce the weight ratios of $0.33,1$, and 3 . As shown in Table 1, compounds with TMTD and CBS were also prepared and tested for comparison. These were compounds $1,5,6,10,11,15,16,20,21,25,26,30,31,35,36$ and 40 . The loading of $\mathrm{ZnO}$, stearic acid, processing oil, and carbon black and silica fillers were kept constant at $2 \mathrm{phr}, 0.5 \mathrm{phr}, 4 \mathrm{phr}$, and $60 \mathrm{phr}$, respectively. Compounds 1-15 and compounds 21-40 had 0.5 phr elemental sulfur, whereas, compounds $16-20$, had 0.335 phr elemental sulfur. 
The compression set of the rubber vulcanizate increased progressively as the CBS/TMTD weight ratio in the cure system was raised, irrespective of the filler type and loading of elemental sulfur. However, this was not the case for compounds $12-14$, and 17-19 (Table 4). Notably, increase in the CBS/TMTD weight ratio and filler type affected the compression set of the rubber in different ways (Fig. 3). The compression set of compounds $7-9$ was $50-60 \%$ lower than that of compounds $2-4$. This suggested that at a constant loading of elemental sulfur, i.e. $0.5 \mathrm{phr}$, and with the same filler type (N330), the rubber set was lower if the amount of CBS and TMTD accelerators in the CBS/TMTD ratio was higher, e.g. 1.25/3.75 (compound 7) rather than 0.4/1.2 (compound 2). Interestingly, the compression set was very low when less elemental sulfur was used in the cure system. For example, the compression set of compound 17 with 0.335 phr elemental sulfur was $12 \%$ lower than that of compound 12 that had 0.5 phr elemental sulfur at the same CBS/TMTD weight ratio of 0.33 and with the same filler type (N330). Note that these compounds had much larger amounts of CBS and TMTD accelerators in the cure system, i.e. 2-6 phr.

The compression set deteriorated noticeably when the filler type was changed. For instance, when N550 replaced N330 in the rubber the compression set increased by $11 \%$ (cf. compound 12 and compound 22). The compression set continued deteriorating when N660 and the silica fillers were used in the rubber. The compression set of the rubber increased by $19 \%$ with N660 (cf. compound 12 and compound 27), by $253 \%$ with the liquid TESPT treated silica (cf. compound 12 and compound 32), and by a similar amount with the silane pre-treated silica (cf. compound 12 and compound 37). Recall that these compounds had 0.5 phr elemental sulfur and large amounts of CBS and 
TMTD in the cure system, i.e. 2-6 phr (Table 1). It is worth mentioning that the compounds cured with CBS had a poorer compression set than those cured with TMTD (Table 4). Therefore, it was concluded that the lowest compression set for the rubber vulcanizate could be achieved with N330 carbon black filler, 0.335 phr elemental sulfur and larger amounts of CBS and TMTD in the cure system, i.e. 2-6 phr. It was interesting to note that small changes in the amount of elemental sulfur, i.e. from 0.5 to $0.335 \mathrm{phr}$, had a more pronounced effect on the compression set than did large changes in the amount of CBS and TMTD in the cure system, i.e. 2-6 phr. Besides, the replacement of N330 with N550, N660 and silica/silane fillers was not beneficial to the compression set of the rubber vulcanizate and in fact the latter had the worse effect on this property.

\section{Factors affecting the compression set of rubber vulcanizates}

The compression set of NR increased by almost $46 \%$ when 10 phr of TESPT pretreated silanized silica was added ${ }^{33}$ and that of ethylene-propylene-diene (EPDM) by nearly $54 \%$ when $30 \mathrm{phr}$ of the same filler was incorporated in the rubber. ${ }^{34}$ It was also reported that the compression set of EPDM rose by approximately $144 \%$ as the loading of the filler was raised to $60 \mathrm{phr} .{ }^{34}$ Clearly, in the case of the TEPST pre-treated precipitated silica, the compression set was influenced by both the filler loading and chemical composition of the rubber. Additionally, our results showed that the compression set of NBR was affected by increase in the CBS/TMTD weight ratio in the cure system, at least for some of the compounds tested (Figure 3), as well as the filler type. This new information will be useful for the design and compounding of rubber seals. 


\section{Correlation between the crosslink density, $\Delta$ torque and compression set of the} rubber vulcanizates

When the crosslink density and $\Delta$ torque values were examined in Tables $2 \& 3$, as expected there was a clear correlation between the two. In most cases, as the crosslink density increased so did the $\Delta$ torque. However, there were some exceptions. For example, for compounds 37-39 there was no obvious trend. Remember that $\Delta$ torque is an indication of crosslink density changes in the rubber. When the compression set results in Table 4 were re-examined in the light of the crosslink density and $\Delta$ torque values in Tables $2 \& 3$, it was obvious that crosslink density was the main factor in determining the compression set of the rubber vulcanizate. For example, for compounds $2-4$, the crosslink densities were $297-235 \mathrm{~mol} / \mathrm{m}^{3}$, and the compression set of these compounds were $17.51-37.41 \%$, respectively. As the crosslink density decreased, the compression set went up except for compounds 12-14 and 17-19. Note however that the silica-filled rubber vulcanizates had much higher crosslink densities (compounds 3140; Table 3). This was because TESPT is a sulfur-bearing silane and was used as a coupling agent. The silica particles reacted with the rubber chains via the tetrasulfane groups of TESPT and produced additional crosslinks to those monosulfidic ones formed by elemental sulfur. ${ }^{17}$

As stated earlier, EV cure systems have predominantly high mono-sulfidic and little or no polysulfidic cross-link content. ${ }^{10,11}$ The formation of mono sulfidic links between the rubber chains reduced chain mobility and inhibited chain slippage when a load was applied to the rubber in the compression tests. This in turn reduced set or permanent deformation of the rubber after the applied load was removed. All the indications were 
that adjusting the crosslink density was the most effective method for influencing the compression set of the rubber vulcanizate. This was in line with a previous study. ${ }^{6,7}$ Effect of different combinations of accelerators on the compression set of some NR vulcanizates

Francis and co-workers ${ }^{35}$ examined effect of various solid fillers including HAF carbon black and precipitated silica in the binary systems containing TMTD-amidinothiourea (ATU) and di-benzothiazole-2-yl-disuphide (MBTS)-ATU in NR vulcanization. MBTS is a thiazole type accelerator used for all sulfur curable rubbers. ATU was used as a secondary accelerator and improved the accelerator activity of these systems. The MBTS/ATU and TMTD/ATU weight ratios in the sulfur cure system increased from 0.67 to 2. The compression set of the HAF-filled rubber vulcanizate increased by $13 \%$ as the MBTS/ATU and TMTD/ATU weight ratios in the cure system were raised progressively to their optimum values. A similar trend was also observed for the silica-filled rubber vulcanizate though the rise in the compression set was somewhere between 4 and 10\%. Remarkably, there was no clear correlation between the crosslink density and compression set of the rubber. This was contrary to our results which showed a clear correlation between the two at least for most of the compounds tested (Tables $3 \& 4$ ). It was also encouraging to see that the increase in the compression set as a function of MBTS/ATU and TMTD/ATU weight ratios in the cure system was similar to the trend we observed. It is worth noting there was no correlation between MBTS/ATU and TMTD/ATU weight ratios in the cure system and crosslink density of the rubber. ${ }^{35}$ In our work, the crosslink density decreased as the CBS/TMTD weight ratio was raised progressively. This was because TMTD was a sulfur donor accelerator (Scheme 1) and 
as there was less TMTD in the higher CBS/TMTD weight ratios, hence there was less additional sulfur released to participate in the curing of the rubber and consequently the lower crosslink density.

Correlation among the compression set, tensile strength, elongation at break and hardness of the rubber vulcanizate - Compression set and tensile strength

Compression set and tensile strength - Table 4 shows tensile strength, elongation at break and hardness results for compounds 1-40. There were various trends emerging from these results. For compounds 2-4, 7-9, and 22-24, the tensile strength remained unchanged when the compression set increased, e.g. for compounds 2-4, the tensile strength was on average about $22 \mathrm{MPa}$, when the compression rose by $114 \%$. But for the remaining compounds, the tensile strength improved when the compression set was increased. For instance for compounds $12-14$, the tensile strength increased by $23 \%$ as the compression set went up by $67 \%$. Generally, the tensile strength of the rubber vulcanizates filled with N330 carbon black filler were noticeably superior to those measured for the other compounds. For example, for compounds 2-19, the tensile strength was between 16.7 to $24 \mathrm{MPa}$, and for compounds $22-29$ containing N550 and N660, between 14.6 to $19.6 \mathrm{MPa}$. Notably, the lowest tensile strength, i.e. 3.65 MPa, was recorded for the rubber cured with 8 phr CBS (compound 30) whereas the rubber cured with $1.6 \mathrm{phr}$ TMTD (compound 1) had a much higher tensile strength of $23 \mathrm{MPa}$. Clearly, when these two accelerators were used together in the cure system, they were more beneficial to the rubber properties.

\section{Compression set, elongation at break and hardness}


For most compounds, the elongation at break showed an upward movement as did the compression set. However, this was not the case for compounds $2 \& 3,12 \& 13$, and 17 \& 18 (Table 4). Since higher compression set was due to lower crosslink density (Tables 4), this also explained the higher elongation at break because as crosslink density decreased, the rubber chains were less restricted and could stretch more when load was applied to the rubber. The compression set and rubber hardness did not correlate in an obvious way. For some compounds, e.g. compounds 2-4, the compression set increased by $113 \%$, whereas the hardness reduced only by $1.3 \%$. For the carbon black-filled compounds, the hardness remained between 71 to 80 Shore $\mathrm{A}$ whilst the compression set changed from 5.5 to $37.4 \%$ (Table 4). The silica-filled compounds were the hardest at 80-85 Shore A. As stated earlier, the silica-filled compounds had higher crosslink densities because of the reaction of the tetrasulfide groups of TESPT with the rubber chains, which produced additional crosslinks in the rubber. Previous studies showed no obvious correlation between compression set and mechanical properties such as hardness, tear strength, resilience and abrasion loss. ${ }^{35}$ Our results seemed to confirm these earlier findings.

\section{Effect of the fillers on the rubber properties}

As the results in Table 4 show, the fillers had different effects on the tensile strength and hardness of the rubber compounds. The highest tensile strength was recorded for the compounds with N330 carbon black filler, i.e. 17-24 MPa. Filler-rubber interaction, which to a large extent controls the rubber reinforcement, is affected by the surface area of the filler. Among the black fillers, N330 had the largest surface area of $78 \mathrm{~m}^{2} / \mathrm{g}$ followed by N550 of $40 \mathrm{~m}^{2} / \mathrm{g}$, and $\mathrm{N} 660$ of $35 \mathrm{~m}^{2} / \mathrm{g}$, respectively. For the compounds 
reinforced with N550 carbon black the tensile strength was around $19 \mathrm{MPa}$, and those with N660, it was slightly lower at 15-19 MPa, respectively. The declining trend in this property matched the decrease in the surface area of the fillers.

The silica filler had a much larger surface area of $175 \mathrm{~m}^{2} / \mathrm{g}$ and therefore it was expected to be a lot more reinforcing than the carbon black fillers. Reinforcing effect of the same amount of HAF carbon black and precipitated amorphous silica fillers on the mechanical properties of styrene-butadiene rubber (SBR) was investigated. The study showed that properties such as tensile strength, stored energy density at break, and tear energy were superior for the silica-filled rubber vulcanizate. ${ }^{36}$ This was attributed to the larger surface area of the silica particles. But, this was not the case when our results were examined (Table 4). Thus, it is likely that other factors such as different crosslink structures might have influenced the ability of the silica filler to reinforce the rubber. Recall that in the carbon black-filled compounds the crosslinks formed between the rubber chains and in the silica-filled compounds the links formed between the filler and rubber as well as between the rubber chains. Although higher crosslink densities were measured for the silica-filled compounds (Table 3), the compression set was higher compared with the carbon black-filled compounds, i.e. $27-54 \%$ (Table 4). It was concluded that the extra crosslinks which might have formed between the rubber and filler via the tetrasulfane groups of TESPT had little or no effect on the chains movement within the bulk of the rubber and the compression set was affected mainly by the formation of crosslinks between the rubber chains. In fact, a similar behavior was also reported when $10 \mathrm{phr}$ of TESPT pre-treated precipitated silica was used to reinforce NR. Chemical bonds or crosslinks formed between the rubber and filler via the 
tetrasulfane groups of TESPT. The compression set of the filled rubber reduced by a staggering $33 \%$ when 0.2 phr elemental sulfur was added. In the latter case, crosslinks formed between the rubber chains as well as between the filler and rubber chains. ${ }^{33}$ There are various factors which affect reinforcement of rubber by solid fillers. They are: filler-rubber interaction, ${ }^{37,38}$ filler-filler interaction, ${ }^{39}$, and formation of crosslinks in rubber. ${ }^{10,12}$ Silicas differ from carbon blacks in many ways. Due to the different chemical compositions, different results for surface energy of carbon blacks and silicas were reported. ${ }^{17}$ Surface energy is composed of a dispersive component and a specific component. The dispersive component, which is high in carbon black but low in silica, is a measure of rubber-filler interaction and specific or polar component, which is low in carbon black and high in silica, is a measure of filler-filler interaction. For rubber grade N330, N550 and N660 furnace carbon blacks, the dispersive component of surface free energy increased in direct proportion to their surface areas, i.e. $78-35 \mathrm{~m}^{2} / \mathrm{g}$, respectively. Thus, the improvement seen in the tensile strength when N330 was replaced with N550 and N660, was due to higher dispersive component of surface free energy, which caused stronger rubber-filler interaction as expected.

In situ reinforcement for an NBR rubber vulcanizate, which was premixed with precipitated silica (VN3) and a coupling agent, was investigated. ${ }^{40}$ It was reported that the reinforcement efficiency improved with the increase of mechanically premixed silica. The simultaneous use of VN3 and silane promoted the formation of large silica particles and clusters with a relatively good dispersion in the rubber. This was due to the surface modification of VN3 by the silane, which worked as a dispersion agent for the silica particles in the rubber. This morphology brought about excellent reinforcement effect for 
the NBR vulcanizate. Ansarifar and co-workers ${ }^{24}$ used $60 \mathrm{phr}$ precipitated silica filler to crosslink and reinforce the mechanical properties of an NBR rubber. The silica surface was pre-treated with TESPT to chemically bond silica to the rubber. The hardness, tensile strength and elongation at break increased substantially because of the filler. The bound rubber and crosslink density measurements indicated strong interaction between the filler and rubber. Generally, precipitated silica pre-treated with TESPT dispersed a lot better in rubber than the silica and liquid TESPT did in situ. ${ }^{22,23}$ Besides, the mechanical properties of the rubber vulcanizates were significantly better with the pre-treated silica. ${ }^{23,24}$ Yet, as shown in Table 4, there was little evidence of this in the present work, and the picture for the silica/silane system was less clear.

As mentioned earlier, ${ }^{6,7,24,40}$ there are numerous factors which affect the mechanical properties of NBR rubber vulcanizates. A more accurate assessment of the effect of the filler type on the compression set, tensile strength, elongation at break, and hardness could not be done because contribution from the silica/TESPT system to the rubber reinforcement was not certain and in addition, the crosslink structures and crosslink densities differed much from one compound to another.

\section{CONCLUSIONS}

From this study, it was concluded that:

- The lowest compression set was achieved for the rubber vulcanizate with N330 carbon black, $0.335 \mathrm{phr}$ of elemental sulfur and high loading of CBS and TMTD accelerators in the CBS/TMTD weight ratio. But in most cases, as the CBS/TMTD weight ratio was increased from 0.33 to 3 , the compression set deteriorated. 
- Among the fillers, carbon black caused less compression set of the rubber vulcanizate than the silica/TESPT system did.

- For some compounds, the tensile strength remained unchanged when the compression set increased and for others, the tensile strength and compression set followed the same trend. Consequently, there was no obvious correlation between the two properties. Generally, the tensile strength of the rubber vulcanizates filled with N330 carbon black was superior to that of the other compounds.

- The lowest tensile strength was recorded for the rubber cured with 8 phr CBS whereas the rubber cured with $1.6 \mathrm{phr}$ TMTD had a much higher tensile strength of 23 MPa. When the two accelerators were used together in the cure system, they were more beneficial to the rubber properties.

\section{ACKNOWLEDGEMNT}

This work was carried out in collaboration with Pars Mobbadel Toos Co. of Iran. The authors thank them for their support of this work. The authors also express their gratitude to the staff at the polymer testing laboratory at Ferdowsi University of Mashhad in Iran. 


\section{REFERENCES}

1. http://www.allsealsinc.com/allseals/Orings/or13.htm

2. US Patent 5362787 A, Hung D. Ngoc, Guy P. R. Duval. The Goodyear Tyre \& Rubber co. 1993.

3. Sonnenschein, M.; Prange, R.; Schrock, A. Polymer 2007, 48, 616.

4. Gates, T.; Veazie, D.; Brinson, L. J. Compos. Mat. 1997, 31, 2478.

5. Le, H.; LLisch, S.; Radusch, H. Polymer 2009, 50, 2294.

6. Morrel, P.; Patel, M.; Skinner, A. Polym. Test 2003, 22, 652.

7. Chang, D. M. Paper presented at a meeting of the rubber division, American Chemical Society, Lag Vegas, Nevade, May 1980, 170, 20.

8. Ciullo, P. A.; Hewitt, N "The Rubber Formulary", Noyes Publications, New York, USA, 1999.

9. Saeed, F.; Ansarifar, A.; Ellis, R. J.; Haile-Meskel, Y.; Shafiq Irfan, M. J. Appl. Polym. Sci. 2012, 123, 1518.

10. Nasir, M.; Teh, G. K. Eur. Polym. J. 1988, 24, 733.

11. Datta, R. N "Rubber Curing Systems", Rapra Report 2002, 12, 3.

12. Kok, C. M.; Yee, V. H. Eur. Polym. J. 1986, 22, 341.

13. Gillan, K.; Celina, M.; Bernstein, R. Polym. Degrad. Stabil. 2003, 82, 25.

14. Warrick, E. L.; Pierce, O. R.; Polmanteer, K. E.; Saam, J. C. Rubber Chem. Technol. 1979, 52, 437.

15. Hair, M. L.; Hertl. W. J. J Phys. Chem. 1970, 74, 91.

16. Hockley, J. A.; Pethica. B. A. Trans. Faraday Soc. 1961, 57, 2247.

17. Wolff, S.; GÖrl, U.; Wang, M. J.; Wolff, W. Eur. Rubb. J. 1994, 16, 16. 
18. Wolff. S. Rubber Chem. Technol. 1996, 69, 325.

19. Ansarifar, A.; Lim, H. P.; Nijwahan, R. Int. J. Adhes. Adhes. 2004, $24,9$.

20. GÖrl. U.; Panenka R. Silanisierte Kieselsauren-Eine neue Produktklasse für zeitgemabe. Mischungsentwicklung Kautsch Gummi Kunstst 1993, 46, 538.

21. Wolff, S. Rubber Chem. Technol. 1982, 55, 976.

22. Ansarifar, A.; Nijhawan, R.; Nanapoolsin, T.; Song, M. Rubber Chem. Technol. 2003, 76, 1290.

23. Ostad Movahed, S.; Ansar Yasin, K.; Ansarifar, A.; Song, M.; Hameed. S. J. Appl. Polym. Sci. 2008, 109, 869.

24. Ansar Yasin, K.; Ansarifar, A.; Hameed, S.; Wang, L. Polym. Adv. Technol. 2011, $22,215$.

25. http://monographs.iarc.fr/ENG/Monographs/vol93/mono93-6.pdf

26. Information, silanized Silica (COUPSIL), No. 6030.1, Degussa AG, Germany 1994.

27. British Standard Institution, Physical testing of rubber - Curemeter. British Standard 903-A60.1, 2000.

28. Saiwari, S.; Dierkes, W.K.; Noordermeer, J.W.M. KGK Kautschuk, Gummi, Kunststoffe, 2013, 66, 20.

29. Baldwin, F P.; Verstrate, G. Rubber Chem. Technol. 1972, 45, 709.

30. Bani, A.; Polacco, G.; Gallone, G. J. Apply Polym. Sci. 2011, 120, 2904.

31. British standards institution, Method for determination of tensile stress strain properties, BS 903, A2, UK 1995.

32. British Standards Institution, Physical testing of rubber: Method for determination of hardness, BS 903, A26, London, UK, 1995. 
33. Ansarifar, A.; Shiah, S. F.; Bennett, M. Int. J. Adhes. Adhes. 2006, 26, 454.

34. Ansarifar, A.; Saeed, F. Polym. Comp. 2013, 34, 2013.

35. Mathew, C.; Elizabeth, Mini V. T.; Kuriakose, D.; Francis, D. J. J. Appl. Polym. Sci. 1996, 59, 365.

36. Ansarifar, A.; Holmes, S. P. J. Rubb. Res. 2005, 8, 191.

37. Suzuki, N.; Ito, M.; Ono, S. J. Apply. Polym. Sci. 2005, 95, 74.

38. Leblanc, J. L. J Apply Polym Sci. 2000, 78, 1541.

39. Fröhlich, J.; Niedermeier, W.' Luginsland, H. D. Composites, 2005, Part A36, 449.

40. Murakami, K.; Osanal, S.; Shigekuni, M.; Ito, S.; Tanahashi, H. Rubber Chem. Technol. 1999, 72, 119. 


\section{Scheme captions}

Scheme 1- Showing the chemical structure of TMTD.

Scheme 2 - Showing the chemical structure of CBS.

\section{Figure captions}

Figure 1 - Compound temperature vs mixing time for some of the rubber compounds tested.

Figure 2 - Typical ODR cure traces for compounds 26-30.

Figure 3 - Compression set vs CBS/TMTD weight ratio for the rubber compounds tested. Note that the data for compounds 12-14 and 17-19 were excluded because they showed no obvious trend. 
Table 1- Rubber compound formulations (phr)

\begin{tabular}{|c|c|c|c|c|c|c|c|c|c|c|c|c|c|}
\hline Code & NBR & N330 & N550 & N660 & $\begin{array}{l}\text { Silica/ } \\
\text { Liquid } \\
\text { TESPT }\end{array}$ & $\begin{array}{l}\text { TESPT } \\
\text { Pre-treated } \\
\text { silica }\end{array}$ & $\mathrm{ZnO}$ & $\begin{array}{c}\text { Stearic } \\
\text { acid }\end{array}$ & WB42 & Sulfur & TMTD & CBS & $\begin{array}{l}\text { CBS/TMTD } \\
\text { weight ratio }\end{array}$ \\
\hline 1 & 100 & 60 & - & - & - & - & 2 & 0.5 & 4 & 0.5 & 1.6 & - & - \\
\hline 2 & 100 & 60 & - & - & - & - & 2 & 0.5 & 4 & 0.5 & 1.2 & 0.4 & 0.33 \\
\hline 3 & 100 & 60 & - & - & - & - & 2 & 0.5 & 4 & 0.5 & 0.8 & 0.8 & 1 \\
\hline 4 & 100 & 60 & - & - & - & - & 2 & 0.5 & 4 & 0.5 & 0.4 & 1.2 & 3 \\
\hline 5 & 100 & 60 & - & - & - & - & 2 & 0.5 & 4 & 0.5 & - & 1.6 & - \\
\hline 6 & 100 & 60 & - & - & - & - & 2 & 0.5 & 4 & 0.5 & 5 & - & - \\
\hline 7 & 100 & 60 & - & - & - & - & 2 & 0.5 & 4 & 0.5 & 3.75 & 1.25 & 0.33 \\
\hline 8 & 100 & 60 & - & - & - & - & 2 & 0.5 & 4 & 0.5 & 2.5 & 2.5 & 1 \\
\hline 9 & 100 & 60 & - & - & - & - & 2 & 0.5 & 4 & 0.5 & 1.25 & 3.75 & 3 \\
\hline 10 & 100 & 60 & - & - & - & - & 2 & 0.5 & 4 & 0.5 & - & 5 & - \\
\hline 11 & 100 & 60 & - & - & - & - & 2 & 0.5 & 4 & 0.5 & 8 & - & - \\
\hline 12 & 100 & 60 & - & - & - & - & 2 & 0.5 & 4 & 0.5 & 6 & 2 & 0.33 \\
\hline 13 & 100 & 60 & - & - & - & - & 2 & 0.5 & 4 & 0.5 & 4 & 4 & 1 \\
\hline 14 & 100 & 60 & - & - & - & - & 2 & 0.5 & 4 & 0.5 & 2 & 6 & 3 \\
\hline 15 & 100 & 60 & - & - & - & - & 2 & 0.5 & 4 & 0.5 & - & 8 & - \\
\hline 16 & 100 & 60 & - & - & - & - & 2 & 0.5 & 4 & 0.335 & 8 & - & - \\
\hline 17 & 100 & 60 & - & - & - & - & 2 & 0.5 & 4 & 0.335 & 6 & 2 & 0.33 \\
\hline 18 & 100 & 60 & - & - & - & - & 2 & 0.5 & 4 & 0.335 & 4 & 4 & 1 \\
\hline 19 & 100 & 60 & - & - & - & - & 2 & 0.5 & 4 & 0.335 & 2 & 6 & 3 \\
\hline 20 & 100 & 60 & - & - & - & - & 2 & 0.5 & 4 & 0.335 & $5-$ & 8 & - \\
\hline 21 & 100 & - & 60 & - & - & - & 2 & 0.5 & 4 & 0.5 & 8 & - & - \\
\hline 22 & 100 & - & 60 & - & - & - & 2 & 0.5 & 4 & 0.5 & 6 & 2 & 0.33 \\
\hline 23 & 100 & - & 60 & - & - & - & 2 & 0.5 & 4 & 0.5 & 4 & 4 & 1 \\
\hline 24 & 100 & - & 60 & - & - & - & 2 & 0.5 & 4 & 0.5 & 2 & 6 & 3 \\
\hline 25 & 100 & - & 60 & - & - & - & 2 & 0.5 & 4 & 0.5 & - & 8 & - \\
\hline 26 & 100 & - & - & 60 & - & - & 2 & 0.5 & 4 & 0.5 & 8 & - & - \\
\hline 27 & 100 & - & - & 60 & - & - & 2 & 0.5 & 4 & 0.5 & 6 & 2 & 0.33 \\
\hline 28 & 100 & - & - & 60 & - & - & 2 & 0.5 & 4 & 0.5 & 4 & 4 & 1 \\
\hline 29 & 100 & - & - & 60 & - & - & 2 & 0.5 & 4 & 0.5 & 2 & 6 & 3 \\
\hline 30 & 100 & - & - & 60 & - & - & 2 & 0.5 & 4 & 0.5 & - & 8 & - \\
\hline 31 & 100 & - & - & - & 60 & - & 2 & 0.5 & 4 & 0.5 & 8 & - & - \\
\hline 32 & 100 & - & - & - & 60 & - & 2 & 0.5 & 4 & 0.5 & 6 & 2 & 0.33 \\
\hline 33 & 100 & - & - & - & 60 & - & 2 & 0.5 & 4 & 0.5 & 4 & 4 & 1 \\
\hline 34 & 100 & - & - & - & 60 & - & 2 & 0.5 & 4 & 0.5 & 2 & 6 & 3 \\
\hline 35 & 100 & - & - & - & 60 & - & 2 & 0.5 & 4 & 0.5 & - & 8 & - \\
\hline 36 & 100 & - & - & - & - & 60 & 2 & 0.5 & 4 & 0.5 & 8 & - & - \\
\hline 37 & 100 & - & - & - & - & 60 & 2 & 0.5 & 4 & 0.5 & 6 & 2 & 0.33 \\
\hline 38 & 100 & - & - & - & - & 60 & 2 & 0.5 & 4 & 0.5 & 4 & 4 & 1 \\
\hline 39 & 100 & - & - & - & - & 60 & 2 & 0.5 & 4 & 0.5 & 2 & 6 & 3 \\
\hline 40 & 100 & - & - & - & - & 60 & 2 & 0.5 & 4 & 0.5 & - & 8 & - \\
\hline
\end{tabular}


Table 2- Curing properties of the rubber compounds

\begin{tabular}{|c|c|c|c|c|}
\hline Compound no. & $t_{90}$ (m.s) & $\Delta$ Torque $(\mathrm{dN} \mathrm{m})$ & $t_{s 1}$ (m.s) & CRI $\left(\min ^{-1}\right)$ \\
\hline 1 & 6:01 & 38.77 & $1: 47$ & 23.56 \\
\hline 2 & $6: 59$ & 29.34 & 2:04 & 20.35 \\
\hline 3 & $6: 46$ & 28.87 & $2: 03$ & 21.17 \\
\hline 4 & 7:06 & 22.29 & $2: 25$ & 21.28 \\
\hline 5 & $8: 49$ & 11.30 & 3:55 & 20.38 \\
\hline 6 & $8: 44$ & 58.50 & $1: 47$ & 14.37 \\
\hline 7 & $6: 23$ & 53.66 & $1: 48$ & 21.85 \\
\hline 8 & $6: 17$ & 49.61 & $1: 51$ & 22.57 \\
\hline 9 & $6: 33$ & 41.74 & 2:05 & 22.45 \\
\hline 10 & $9: 28$ & 18.25 & 4:49 & 21.50 \\
\hline 11 & $8: 59$ & 51.00 & $1: 18$ & 13.03 \\
\hline 12 & $7: 33$ & 59.37 & $1: 38$ & 16.92 \\
\hline 13 & $6: 59$ & 57.67 & $1: 54$ & 19.62 \\
\hline 14 & $7: 49$ & 51.99 & $2: 14$ & 17.92 \\
\hline 15 & 9:04 & 25.21 & $4: 12$ & 20.57 \\
\hline 16 & 9:01 & 50.70 & $1: 39$ & 13.56 \\
\hline 17 & $7: 43$ & 55.83 & $1: 49$ & 16.96 \\
\hline 18 & $6: 22$ & 54.31 & 1:51 & 22.15 \\
\hline 19 & $5: 24$ & 40.71 & $2: 10$ & 30.98 \\
\hline 20 & 9:39 & 17.43 & $5: 29$ & 24.03 \\
\hline 21 & $8: 57$ & 49.56 & $1: 40$ & 13.74 \\
\hline 22 & $7: 38$ & 59.09 & $1: 45$ & 16.99 \\
\hline 23 & $6: 10$ & 57.49 & $1: 54$ & 23.40 \\
\hline 24 & $6: 42$ & 48.16 & $2: 13$ & 22.30 \\
\hline 25 & 13:02 & 23.15 & $5: 50$ & 13.88 \\
\hline 26 & $8: 53$ & 54.54 & $1: 40$ & 13.83 \\
\hline 27 & $7: 11$ & 57.62 & $1: 50$ & 18.68 \\
\hline 28 & $6: 36$ & 49.99 & 2:05 & 22.11 \\
\hline 29 & 7:04 & 43.53 & $2: 17$ & 20.90 \\
\hline 30 & $15: 48$ & 21.74 & $6: 27$ & 10.69 \\
\hline 31 & $6: 53$ & 101.54 & $1: 35$ & 28.87 \\
\hline 32 & 5:03 & 84.52 & $1: 29$ & 28.07 \\
\hline 33 & 4:29 & 78.54 & $1: 26$ & 32.76 \\
\hline 34 & 4:43 & 54.78 & $1: 45$ & 31.79 \\
\hline 35 & 3:57 & 5.42 & 1:56 & 49.73 \\
\hline 36 & $7: 35$ & 23.87 & $1: 58$ & 17.76 \\
\hline 37 & $5: 41$ & 21.14 & $2: 11$ & 28.59 \\
\hline 38 & 4:39 & 31.81 & 2:13 & 41.21 \\
\hline 39 & 4:39 & 43.07 & $2: 28$ & 45.63 \\
\hline 40 & $9: 43$ & 20.43 & $6: 40$ & 32.88 \\
\hline
\end{tabular}


Table 3 - Crosslink density and sol \% of compounds 1-40.

\begin{tabular}{|c|c|c|}
\hline Compound no. & Sol content (\%) & $\begin{array}{c}\text { Crosslink density } \\
\left(\mathrm{mol} / \mathrm{m}^{3}\right)\end{array}$ \\
\hline 1 & 1.5 & 363 \\
\hline 2 & 1.6 & 297 \\
\hline 3 & 1.4 & 295 \\
\hline 4 & 1.8 & 235 \\
\hline 5 & 2.4 & 185 \\
\hline 6 & 2.2 & 532 \\
\hline 7 & 3.1 & 475 \\
\hline 8 & 2.8 & 459 \\
\hline 9 & 2.2 & 399 \\
\hline 10 & 3.5 & 240 \\
\hline 11 & 2.8 & 546 \\
\hline 12 & 2.8 & 521 \\
\hline 13 & 3.0 & 459 \\
\hline 14 & 2.4 & 413 \\
\hline 15 & 2.9 & 310 \\
\hline 16 & 3.8 & 285 \\
\hline 17 & 2.9 & 324 \\
\hline 18 & 3.4 & 309 \\
\hline 19 & 2.5 & 281 \\
\hline 20 & 3.4 & 154 \\
\hline 21 & 3.5 & 328 \\
\hline 22 & 3.3 & 362 \\
\hline 23 & 2.5 & 357 \\
\hline 24 & 3.1 & 286 \\
\hline 25 & 3.5 & 157 \\
\hline 26 & 3.5 & 334 \\
\hline 27 & 3.3 & 335 \\
\hline 28 & 2.7 & 307 \\
\hline 29 & 2.8 & 263 \\
\hline 30 & 3.3 & 162 \\
\hline 31 & 3.4 & 483 \\
\hline 32 & 3.8 & 373 \\
\hline 33 & 3.2 & 360 \\
\hline 34 & 3.3 & 248 \\
\hline 35 & 3.1 & 231 \\
\hline 36 & 4.7 & 759 \\
\hline 37 & 4.9 & 600 \\
\hline 38 & 4.7 & 526 \\
\hline 39 & 4.3 & 548 \\
\hline 40 & 4.2 & 464 \\
\hline
\end{tabular}


Table 4- Compression set, tensile strength, elongation at break, and hardness of the compounds.

\begin{tabular}{|c|c|c|c|c|}
\hline Compound no. & $\begin{array}{c}\text { Compression set } \\
(\%)\end{array}$ & $\begin{array}{l}\text { Tensile strength } \\
(\mathrm{MPa})\end{array}$ & $\begin{array}{c}\text { Elongation at break } \\
(\%)\end{array}$ & $\begin{array}{l}\text { Hardness } \\
\text { (shore A) }\end{array}$ \\
\hline 1 & 14.55 & 23.33 & 1084 & 78 \\
\hline 2 & 17.51 & 22.82 & 1358 & 78 \\
\hline 3 & 20.87 & 22.30 & 1328 & 76 \\
\hline 4 & 37.41 & 21.47 & 1576 & 77 \\
\hline 5 & 58.76 & 13.58 & 1867 & 75 \\
\hline 6 & 8.05 & 19.12 & 807 & 80 \\
\hline 7 & 8.75 & 22.83 & 1031 & 79 \\
\hline 8 & 9.69 & 22.15 & 1125 & 78 \\
\hline 9 & 13.95 & 21.93 & 1310 & 76 \\
\hline 10 & 38.94 & 18.47 & 2743 & 72 \\
\hline 11 & 11.71 & 17.88 & 880 & 79 \\
\hline 12 & 7.56 & 19.52 & 799 & 80 \\
\hline 13 & 7.19 & 21.62 & 951 & 79 \\
\hline 14 & 12.65 & 24.02 & 1210 & 78 \\
\hline 15 & 28.95 & 20.97 & 1776 & 75 \\
\hline 16 & 8.91 & 15.10 & 692 & 79 \\
\hline 17 & 6.66 & 16.67 & 613 & 77 \\
\hline 18 & 5.48 & 21.14 & 772 & 80 \\
\hline 19 & 10.45 & 23.08 & 904 & 78 \\
\hline 20 & 37.54 & 13.36 & 1778 & 73 \\
\hline 21 & 8.89 & 17.07 & 744 & 79 \\
\hline 22 & 8.41 & 18.82 & 677 & 78 \\
\hline 23 & 8.69 & 19.61 & 679 & 78 \\
\hline 24 & 12.40 & 19.00 & 836 & 77 \\
\hline 25 & 42.49 & 5.65 & 1163 & 73 \\
\hline 26 & 7.77 & 16.50 & 747 & 78 \\
\hline 27 & 9.02 & 14.58 & 587 & 76 \\
\hline 28 & 9.37 & 18.36 & 847 & 75 \\
\hline 29 & 28.05 & 19.14 & 1047 & 71 \\
\hline 30 & 52.50 & 3.65 & 1565 & 70 \\
\hline 31 & 25.60 & 12.89 & 859 & 88 \\
\hline 32 & 26.70 & 15.42 & 1444 & 85 \\
\hline 33 & 31.50 & 18.90 & 1658 & 83 \\
\hline 34 & 54.00 & 20.60 & 2743 & 82 \\
\hline 35 & 56.05 & 21.50 & 2855 & 81 \\
\hline 36 & 31.27 & 15.63 & 482 & 86 \\
\hline 37 & 26.33 & 17.72 & 633 & 81 \\
\hline 38 & 27.73 & 19.33 & 733 & 83 \\
\hline 39 & 32.72 & 21.92 & 1042 & 80 \\
\hline 40 & 59.05 & 6.44 & 2748 & 77 \\
\hline
\end{tabular}




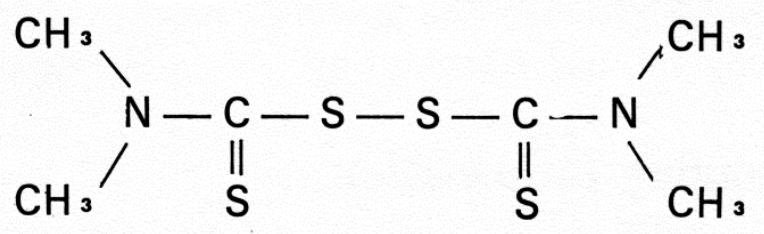

Scheme 1 - Chemical structure of TMTD

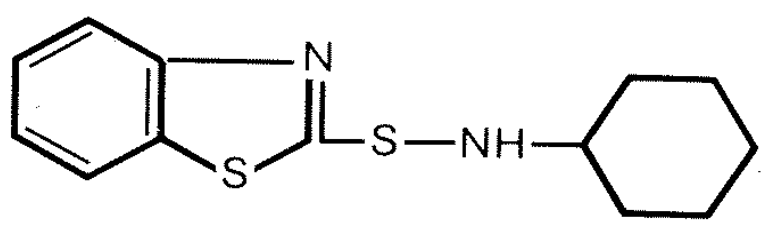

Scheme 2 - Chemical structure of CBS

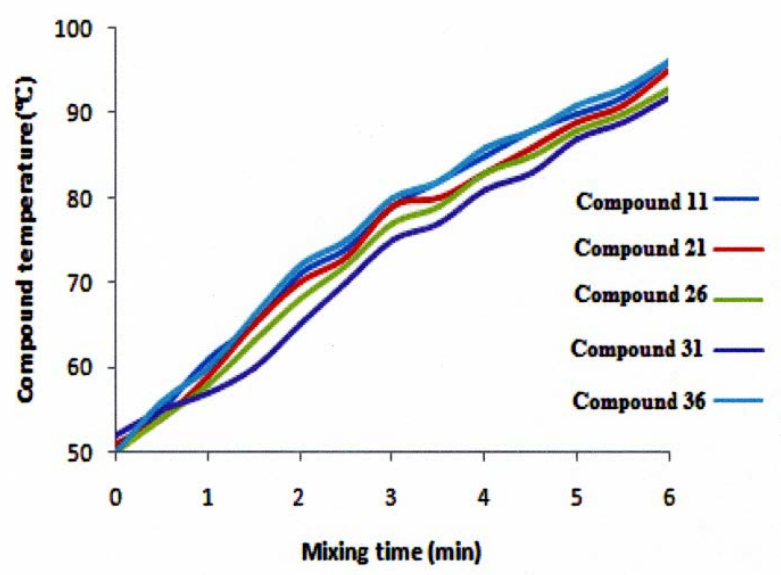

Figure 1 - Compound temperature vs mixing time for some of the rubber compounds tested. 


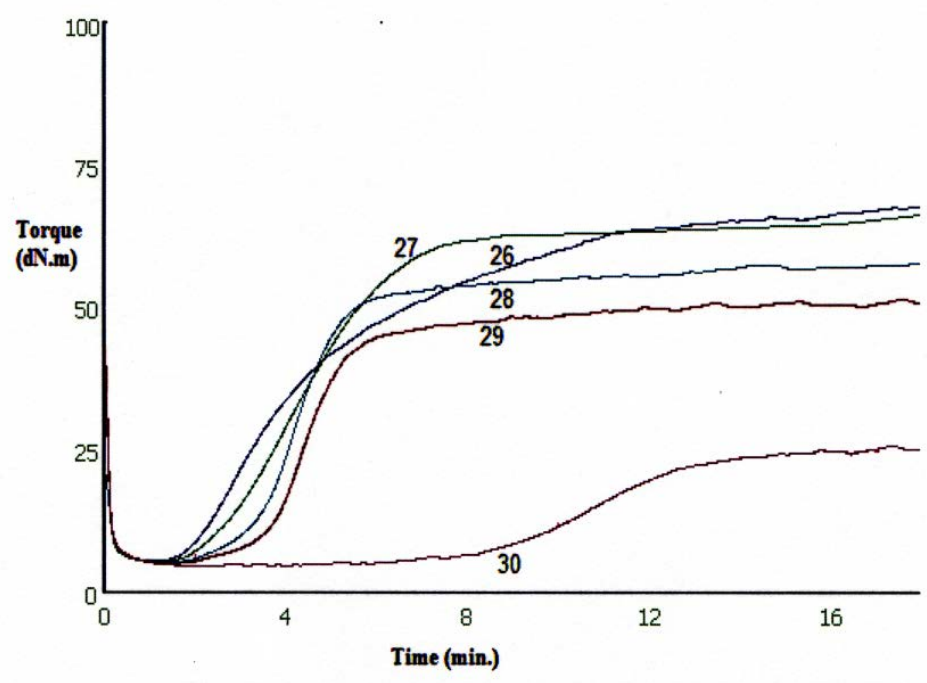

Figure 2 - Typical ODR cure traces for compounds 26-30.

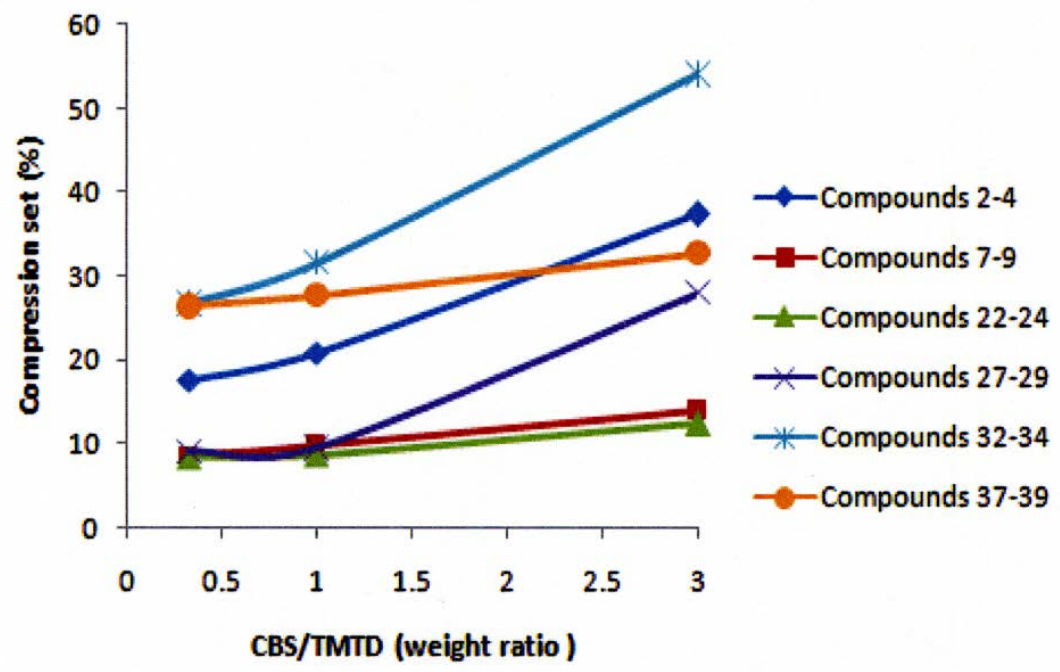

Figure 3 - Compression set vs CBS/TMTD weight ratio for the rubber compounds tested. Note that the data for compounds 12-14 and 17-19 were excluded because they showed no obvious trend. 